\title{
The role of transforming growth factor beta in tertiary dentinogenesis
}

\author{
Tetiana Haniastuti ${ }^{1}$, Phides Nunez ${ }^{2}$, and Ariadna A. Djais ${ }^{3}$ \\ ${ }^{1}$ Department of Oral Biology, Gadjah Mada University, Indonesia \\ ${ }^{2}$ Division of Oral Ecology in Health and Infection, Niigata University, Japan \\ ${ }^{3}$ Department of Oral Biology, University of Indonesia, Indonesia
}

\begin{abstract}
The most visible repair response to pulp injury is the deposition of a tertiary dentin matrix over the dentinal tubules of the primary or secondary dentin. Tertiary dentin is distinguished as reactionary and reparative dentin, depending on the severity of the initiating response and the conditions under which the newly deposited dentin matrix was elaborated. Transforming growth factor beta $(T G F-\beta)$ superfamily is a large group of growth factors that serve important roles in regulating cell growth, differentiation, and function. Members of this superfamily have been implicated in the repair process of the dental tissue after injury. Although numerous studies have proved that those bioactive molecules carry out an important role in the formation of tertiary dentin, comprehensive report regarding that phenomenon is not yet available. This review article aimed to summarize the role of TGF- $\beta$ on tertiary dentinogenesis during the progression of a carious lesion.
\end{abstract}

Key words: transforming growth factor beta, tertiary dentinogenesis, reactionary dentin, reparative dentin

Correspondence: Tetiana Haniastuti, c/o: Bagian Biologi Oral, Fakultas Kedokteran Gigi Universitas Gadjah Mada. Jln. Denta no. 1, Sekip Utara Yogyakarta 55281, Indonesia. E-mail: haniastuti@yahoo.com

\section{INTRODUCTION}

The complex structural composition of teeth provides hardness and durability as a barrier against bacterial infection. When a carious lesion breaks down this barrier, repair takes place to prevent further caries progression; hence, preventing invasion of the pulp chamber by the bacteria. The capacity of pulp cells to resist and repair injuries is fundamental to maintain the integrity and homeostasis of the dental organ. In an adult pulp, cell division and the secretory activity of odontoblasts are limited, but these processes may be re-activated after injury. The most common and well-known feature of pulp repair is the formation of tertiary dentin, ${ }^{1}$ which can be classified as being reactionary or reparative in origin, depending on the severity of the initiating response and the conditions under which the newly deposited dentin matrix was formed. ${ }^{2}$

A number of studies have reported the presence of tertiary dentin in $63.6 \%$ of teeth with carious lesions and found that it often occurs in combination with dentinal sclerosis. ${ }^{3}$ The formation of the tertiary dentin on the pulpal aspect of stimulated dentinal tubules occurs in human deciduous teeth ${ }^{4}$ as well as in permanent teeth. ${ }^{5}$ It starts during the active stage of the carious process and continues after lesion arrest. ${ }^{6}$ The rate of carious attack seems to be an influencing factor since more dentin is formed in response to a slowly progressing chronic caries than to a rapidly advancing acute caries. ${ }^{3}$

Transforming growth factor beta $(\mathrm{TGF}-\beta)$ is a multifunctional regulator of a variety of cellular functions, such as cell proliferation, differentiation, and matrix synthesis. Recent studies showed that this substance has a significant role in the immune response ${ }^{7}$ and tissue repair ${ }^{8}$ of the dental pulp. TGF- $\beta$ has also been implicated in induction of odontoblast-like cell differentiation and in signaling primary odontoblasts during dentin repair. Several in vivo studies have demonstrated the effects of dentin matrix preparation containing this bioactive molecule on both reactionary and reparative dentinogenesis. ${ }^{9-11}$

Recently, numerous studies regarding tertiary dentinogenesis and various aspects related to it have already been reported. However, there is not any comprehensive report discussing this phenomenon. This review article will briefly summarize the role of TGF- $\beta$ on tertiary dentinogenesis during the progression of a carious lesion.

TGF- $\beta$

The TGF- $\beta$ super family comprises over 40 different proteins, most of which can be classified into three broad groupings of TGF- $\beta$ s (isoforms TGF- $\beta 1$, TGF- $\beta 2$, TGF- $\beta 3$, TGF- $\beta 5$ ), BMP-bone morphogenetic proteins (BMP-2, BMP-3, BMP-4, BMP-5, BMP-6, BMP7 and BMP-8), and the activins/inhibins. Each of them is capable of regulating a fascinating array of cellular processes including cell proliferation, lineage determination, differentiation, motility, adhesion, and death. Expressed in complex temporal and tissue-specific patterns, TGF- $\beta$ and related factors play prominent roles in the development, homeostasis, and repair of virtually all tissues in organisms. ${ }^{12}$ In addition, these molecules also have mitogenic effects and 
a regulatory role in matrix biosynthesis. Collectively, these factors account for a substantial portion of the intercellular signals governing cell fate. ${ }^{13}$

TGF- $\beta$ has been implicated as a key mediator in odontoblast differentiation and dentin mineralization. Members of this super family have been implicated both in aspects of tooth development and repair of the dental tissue after injury. ${ }^{9}$ A previous study by $\mathrm{Hu}$ et al. ${ }^{14}$ showed that TGF- $\beta$ as a pulp-capping medicament enhances reparative dentin formation in rat molars.

The presence of TGF- $\beta$ in the dentin matrix has been reported $^{15}$ and measured by ELISA. ${ }^{16}$ TGF- $\beta$ also has been immunolocalized in the dentin matrix at the ultra structural level. ${ }^{17}$ In humans, odontoblasts and other cells of the pulp show the presence of both TGF- $\beta$ receptors I and II with odontoblasts showing the strongest expression. ${ }^{18}$ McLachlan et al. ${ }^{19}$ found that genes of the TGF- $\beta$ family members and their receptors are predominantly expressed by odontoblasts in healthy teeth and generally show higher levels of expression in odontoblasts and pulpal tissue from carious teeth. Sloan et al. ${ }^{20}$ reported that TGF- $\beta$ is normally expressed in both healthy and carious molar teeth in humans. They have identified all three TGF- $\beta$ isoforms in mature human odontoblasts. In their study, odontoblasts cells, pulpal fibroblasts, and endothelial cells were stained to varying degrees for TGF- $\beta 1,2$ and 3 , with TGF- $\beta 3$ showing the greatest intensity and TGF- $\beta 1$ the weakest intensity; however, TGF- $\beta 1$ showed significantly increased staining intensity within the odontoblast and pulpal cells of the carious teeth. In addition, a study by Piatelli et al. ${ }^{21}$ showed that in the odontoblastic and subodontoblastic layer of specimens with irreversible pulpitis, there was a higher expression of TGF- $\beta 1$ than in normal healthy specimens.

\section{Tertiary dentinogenesis}

The response of tertiary dentinogenesis is one of repair or wound-healing as observed after injury to many other tissues of the body. When a carious lesion has invaded dentin, the pulp usually responds by depositing a layer of tertiary dentin over the dentinal tubules of the primary or secondary dentin that communicate with the carious lesion. Secretion of tertiary dentin matrix is restricted to those odontoblasts directly affected by the injury process. ${ }^{19}$

Tertiary dentin differs morphologically from primary dentin reflecting their variations in molecular mechanism of formation. ${ }^{22}$ According to Olgart and Bergenholtz, ${ }^{23}$ compared with primary dentin, tertiary dentin is less sensitive to thermal, osmotic, and evaporative stimuli. The tubules of tertiary dentin tend to be more irregular with larger lumina. In some cases no tubules are formed. The degree of irregularity of tertiary dentin is determined by factors such as the amount of inflammation present, the extent of cellular injury, and the state of differentiation of the replacement odontoblasts.

In addition, tertiary dentin is less permeable to externally derived matter than primary dentin. Along the border zone between primary and tertiary dentin, the walls of dentinal tubules are thickened and the tubules are frequently occluded with material resembling peritubular dentin. The border zone thus appears to be considerably less permeable than ordinary dentin and may serve as a barrier to the ingress of bacteria and their products. ${ }^{23}$ A study by Kim et al. ${ }^{3}$ revealed that the accumulation of pulpal dendritic cells is reduced after tertiary dentin formation, which may indicate the reduction of incoming bacterial antigens.

Tertiary dentin has been defined as the dentin deposited on the pulpal aspects of primary or secondary dentin at sites corresponding to areas of external irritations. ${ }^{4}$ A number of terms have been used to describe this dentin such as irregular secondary dentin, reactionary dentin, reparative dentin, and irritation dentin, all reflecting its varied etiology. Smith et al. ${ }^{2}$ has re-defined it in relation to the nature of the injury to attempt a better discrimination of the responses occurring in the dentin-pulp complex. This has led to adoption of the terms reactionary and reparative dentin to subdivide tertiary dentinogenesis into the responses seen after either survival or death of the primary odontoblast population, respectively.

\section{Reactionary dentinogenesis}

The term reactionary dentinogenesis has been adopted to describe the secretion of a tertiary dentin matrix by primary odontoblasts which have survived injury to the tooth. Typically, this type of dentin will be seen with injury of mild intensity, such as in precavitational stages of active enamel caries and in slowly progressing dentinal lesions. $^{2}$

Slowly progressing carious lesions are characterized by an early increased mineralization of the affected dentin. This hyper mineralization occurs when the caries process is located in the enamel, before it reaches the dentin. By the time the carious lesion reaches the dentin, some of the dissolved mineral salts will reprecipitate within the tubules and form a hyper mineralized transparent zone in the dentin subjacent to the demineralized carious dentin. ${ }^{24}$

Relatively small changes are observed histological in the odontoblast-predentin region associated with slowly progressing caries, but an increased formation of reactionary dentin is apparent. Most of the original odontoblasts survive although they may be somewhat shortened. The reduction of the height of the odontoblasts that form reactionary dentin is not compatible with the increased matrix production. Increased matrix production should result in an increase of intracellular organelles and therefore larger formative cells. It is likely that the subodontoblastic cells and a new generation of odontoblastlike cells contribute to the matrix production under this condition. If the original odontoblast continues to form dentin, the tubules extend from the primary dentin into secondary and tertiary dentin; thus, these pathways to the pulp are kept open. The subodontoblastic region remains virtually unaltered morphologically, but the cell-free zone is often absent, possibly due to the altered physiology of the area. Other components normally present are found, 
including fibroblasts, undifferentiated cells, and dendritic cells. $^{24}$

Tertiary dentin formed in the case of a superficial carious lesion may resemble primary dentin in terms of tubularity and degree of mineralization. In general, the tubules of reactionary dentin continue with those of secondary dentin, while the thickness of the newly formed layer is related to the intensity and duration of the stimulus. The reactionary dentin possesses an organic matrix as well as a mineral content similar to those found in primary and secondary dentin. ${ }^{25}$

\section{Reparative dentinogenesis}

Reparative dentinogenesis is a term used to describe the secretion of tertiary dentin after the death of the primary odontoblasts underlying the injury. Reparative dentin would arise after an injury of greater intensity and represents a much more complex sequence of biological events, involving progenitor cell recruitment and differentiation as well as an up-regulation of cell secretion. In relation to caries, the formation of reparative dentin can be observed in deep dentinal lesions where clinically, a change in lesion activity has occurred. ${ }^{26}$

In rapid progression of carious lesions, the structure of the tertiary dentin that normally forms in the pulp-predentin region varies, depending on the severity of the attack. Sometimes the reparative tissue has cellular inclusions or atubular like fibro dentin. This is the dentin that is referred to as interface dentin. Provided that this reaction prevents the ingress of excessive reactive agents from the carious lesion, the interface dentin has a barrier effect that may be an essential part of the defense mechanisms in the tooth. Interface dentin with irregular, often atubular dentin forms a barrier between the physiologic secondary dentin and the tertiary dentin. This barrier, which corresponds to the hyaline zone of the dead tract, reduces the permeability of the affected dentin and may make it impermeable because the tubules from primary dentin do not cross the interface dentin. The reparative dentin usually continues to form as tubular dentin after the interface dentin has formed although its structure is more irregular, less mineralized, softer, and contains more organic material than primary dentin. ${ }^{24}$

Reparative dentin is in the majority of cases quite different morphologically from reactionary dentin. It may contain cellular inclusions, which resemble the osteocytes from bone. In addition, its extra cellular matrix contains some noncollagenous proteins that are more typical for bone than for dentin. For these reasons, sometimes the reparative dentin shows an osteodentin appearance. ${ }^{25}$

In rapidly progressing caries, the odontoblasts are often destroyed. Odontoblasts are post mitotic terminally differentiated cells that cannot proliferate to replace subjacent irreversibly injured odontoblasts. Consequently, these primary cells must be replaced by a new generation of odontoblast-like cells. ${ }^{27}$ Therefore, the formation of reparative dentin is a complex sequence of biological process, which is dependent on multiple factors, including the presence of responsive progenitor cells as well as the appropriate inductive molecular signals for induction of proliferation, migration, and differentiation of the new generation of odontoblast-like cells. The derivation of the progenitor cells for these odontoblast-like cells remains unclear although they may be variable. The undifferentiated mesenchymal cells in the cell rich zone adjacent to the odontoblast layer are attractive candidates since they will have experienced a developmental history similar to the primary odontoblasts. Other pulpal cells, including perivascular cells, undifferentiated mesenchymal cells, fibroblasts etc., have also been implicated as progenitors for the odontoblast-like cell. ${ }^{28}$

\section{DISCUSSION}

Odontoblasts are the cells responsible for the formation of dentin as well as provide an innate immune barrier for the tooth. ${ }^{29}$ The main task of odontoblasts is to synthesize and secrete collagens and several non-collagenous proteins from which the dentin organic matrix is formed. Odontoblasts control dentin matrix mineralization by determining the nature of the extra cellular matrix and by controlling the influx of mineral ions. ${ }^{25}$

Odontoblasts secrete dentin matrix components which contain a reservoir of biologically active molecules, such as platelet-derived growth factor, vascular endothelial growth factor, fibroblast growth factor, metalloproteinase and also TGF- $\beta$ super family members. During dentinogenesis, the extra cellular matrix of the dentin is mineralized by deposition of hydroxyapatite onto the fibrous matrix. After mineralization the dentin molecules remain trapped in the mineralized phase bound to matrix components or to hydroxyapatite crystals. ${ }^{30}$ Diffusion of acids from bacterial metabolism during caries could solubilize those bioactive molecules from the soluble tissue compartment of dentin matrix and unmask those bound in the insoluble tissue compartment. Subsequent bacterial proteolytic action during more advanced stages of caries might also contribute to, and possibly modulate, such process. Further, those molecules initiate the healing process, providing chemotactic cues to recruit inflammatory cells and undifferentiated pulpal cells to the injury site, stimulating the angiogenic response, and initiating the subsequent tissue movement for repair. ${ }^{31,32}$

Release of TGF- $\beta$ from the dentin matrix requires its diffusion, presumably mainly through the dentinal tubules, to the pulpal cells for signaling events to occur. Several factors may influence the ability of this agent to participate in such events, including their release in a biologically active form, their interaction with dentin matrix components, either in solubilized form or by immobilization on the insoluble matrix, and the diffusion distance along the dentinal tubules. Much of the TGF- $\beta$ in dentin matrix 


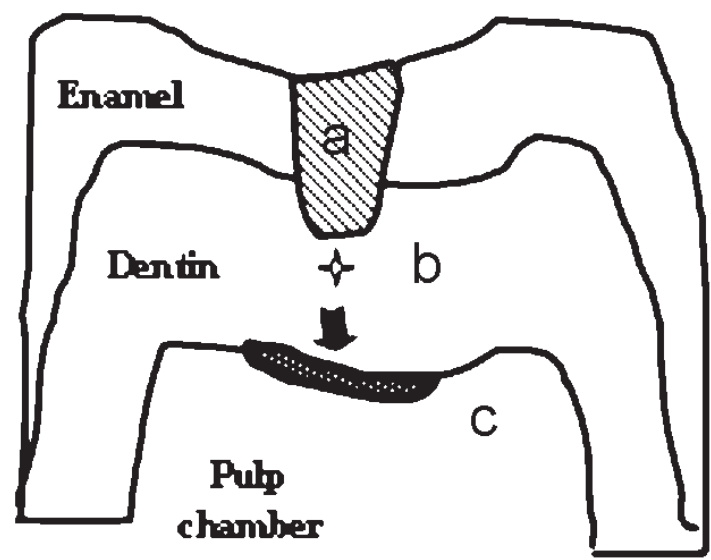

Figure 1. Schematic representation of reactionary dentin formation induced by TGF- $\beta$. (a) Dentin injured by a small carious lesion. (b) Release of TGF- $\beta$ from dentin matrix. (c) Deposition of reactionary dentin by primary odontoblasts.

appears to be in an active form and to be associated with dentin matrix components, which may regulate its availability and biological activity. ${ }^{33}$

A study by Lucchini et al..$^{34}$ showed that differentiated odontoblasts secrete and deposit TGF- $\beta$ into the dentin matrix and can respond to it, thus enabling possible autocrine modes of action. The detection of TGF- $\beta$ receptors I and II on odontoblasts and other pulpal cells demonstrates that an active signaling complex for signal transduction exists on these cells. The target cells for signaling molecules released during carious demineralization will vary, but in terms of repair, the odontoblast will be of prime importance. ${ }^{18}$

TGF- $\beta$ initiates its actions trough Smad signaling pathway by binding to two different classes of serine/ threonine kinase receptors, termed type I and type II, which have been demonstrated in odontoblasts and pulp cells. ${ }^{35}$ Ligand-induced phosphorylation of the type I receptor by the type II receptor results in activation of the type I receptor kinases, which in turn phosphorylate a receptor-regulated Smads $2 / 3$. The phosphorylated Smads 2/3 then associate with Smad4, a common-mediator Smad. These heteromeric complexes are translocated to the nucleus, where they regulate gene transcription by either association with DNAbinding protein or direct binding to promoter sequences of target genes. ${ }^{36}$ Smad6 and Smad7 belong to the inhibitory Smads and act as inhibitors of the TGF- $\beta$ family signaling pathway, probably by competitive interaction with the type I receptor or with Smad4. ${ }^{37}$

During reactionary dentinogenesis (Figure 1), solubilized TGF- $\beta$ s may be able to diffuse to the odontoblasts and pulpal cells localized beneath the damaged region and signal the up-regulation of these cells' secretory activity. ${ }^{27}$ This upregulation of surviving odontoblasts will lead to focal secretion of new matrices at the pulp-dentin interface. $^{2}$ Quite a few studies have demonstrated that

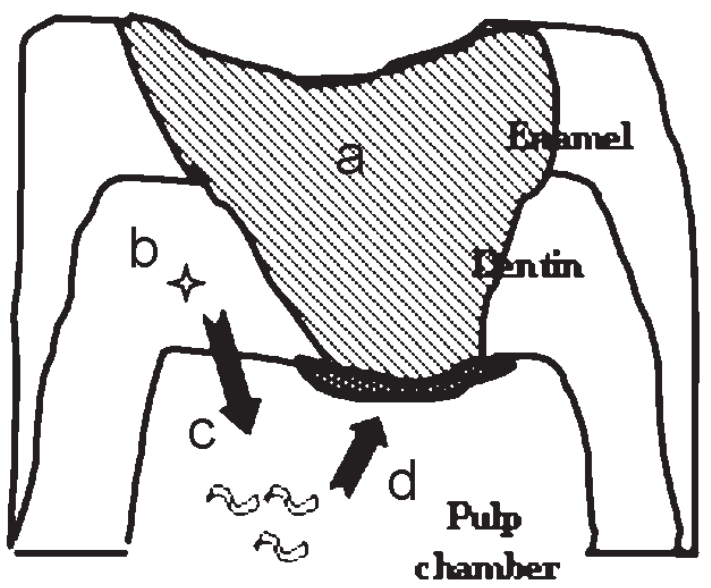

Figure 2. Schematic representation of reparative dentin formation induced by TGF- $\beta$. (a) Pulp exposed by carious lesion. (b) Release of TGF- $\beta$ from dentin matrix . (c) Proliferation, migration and differentiation of odontoblast-like precursor cells into odontoblastlike cells. (d) Deposition of reparative dentin by newly differentiated odontoblast-like cells.

TGF- $\beta$ stimulates the synthesis of extracellular matrices and also initiates odontoblast cytodifferentiation in vitro ${ }^{38}$ and in vivo. ${ }^{39}$ An in vivo study by DenBesten et al. ${ }^{40}$ using transgenic mice overexpressing TGF- $\beta 2$ showed an increase in their dentin mineral apposition relative to their wild-type littermates. TGF- $\beta 2$ has been shown to be present in mature dentin; therefore, it seems that TGF- $\beta 2$ also stimulates odontoblast differentiation in maturing dentin to increase the dentin mineral apposition rate. ${ }^{15}$ An in vitro study by Sloan and $\mathrm{Smith}^{41}$ revealed that TGF- $\beta 1$ and TGF- $\beta 3$ increase the predentin thickness of the cultured tooth in the region immediately adjacent to agarose beads containing those growth factors. The localized increase in the predentin thickness reflects reactionary dentinogenic effect.

TGF- $\beta$ also carries out a significant role in modulating the soft and hard tissue repair following a carious lesion, enhancing reparative dentin formation. The formation of reparative dentin (Figure 2) results from the recruitment and proliferation of the pulp cells which have stem cell properties. A previous study by Pasavant et al. ${ }^{42}$ revealed that TGF- $\beta$ induces the synthesis of secreted protein acidic, rich in protein, which in turn induces dental pulp cells migration toward the odontoblastic layer. ${ }^{43}$ The dental pulp stem cells are attracted to the injury site and differentiate into a second generation of odontoblasts or odontoblast-like cells to replace irreversibly injured odontoblasts. ${ }^{44,45}$ TGF$\beta 1$ may play a role in the differentiation of the pulp cells into preodontoblasts and odontoblasts and in the reparative dentinogenesis process after tissue injury. ${ }^{46}$ A previous in vivo study showed that TGF- $\beta$ induces the differentiation of pre-odontoblasts and formation of functional odontoblastlike cells. ${ }^{47}$ Several studies reported that TGF- $\beta 1$ and TGF$\beta 3$ stimulate proliferation of the cells of the subodontoblast 
layer and formation of odontoblast-like cells. ${ }^{13,41,48}$ In addition, TGF- $\beta 1$ induces type I collagen production by the odontoblastic/subodontoblastic pulp cells. ${ }^{49}$ Huojia et al. ${ }^{50}$ reported that TGF- $\beta 3$ induces ectopic mineralization through upregulation of osteocalcin and type I collagen expression in the dental pulp cells and may regulate the differentiation of the dental pulp stem cells to odontoblasts. Such activities might be important during reparative processes in the dentin-pulp complex after tissue injury.

In conclusion, the dentin-pulp complex has ability to respond to a carious lesion by localized deposition of a tertiary dentin matrix which can be classified as being reactionary or reparative in origin, depending on the severity of the initiating response and the conditions under which the newly deposited dentin matrix was generated. TGF- $\beta$ super family which is captured in the dentin matrix, may be solubilized or exposed during carious demineralization and provides the molecular signaling to initiate tertiary dentinogenesis. In reactionary dentinogenesis, TGF- $\beta$ s stimulate the upregulation of odontoblast cells' synthetic and secretory activities to secrete a reactionary dentin matrix. TGF- $\beta$ s also have the ability to induce the proliferation, migration, and differentiation of odontoblastlike cells from the pulp cells leading to the secretion of reparative dentin.

\section{REFERENCES}

1. Mitsiadis TA, Rahiotis C. Parallels between tooth development and repair: conserved molecular mechanisms following carious and dental injury. J Dent Res 2004; 83:896-902.

2. Smith AJ, Cassidy N, Perry H, Begue-Kirn C, Ruch J-V, Lesot H. Reactionary dentinogenesis. Int J Dev Biol 1995; 39:273-80.

3. Kim S, Trowbridge H, Suda H. Pulpal reaction to caries. In: Cohen S, Burns RC, editors. Pathway of the pulp. $8^{\text {th }}$ ed. St Louis: Mosby, 2002. p. 574.

4. Klinge RF. A microradiographic and electron microscopic study of tertiary dentin in human deciduous teeth. Acta Odontol Scand 1999; 57:87-92.

5. Stanley HR, Pereira JC, Spiegel E, Broom C, Schultz M. The detection and prevalence of reactive and physiologic sclerotic dentin, reparative dentin and dead tracts beneath various type of dental lesions according to tooth surface and age. J Pathol 1983; 12:257-89.

6. Massler M. Pulpal reactions to dental caries. Int Dent J 1967; 17:441-60.

7. Yongchaitrakul T, Pasavant P. Transforming growth factor- $\beta 1$ upregulates the expression of nerve growth factor through mitogenactivated protein kinase signaling pathways in dental pulp cells. Eur J Sci 2007; 115:57-63.

8. Farges JC, Romeas A, Melin M, Pin JJ, Lebecque S, Lucchini M, Bleicher F, Magloire H. TGF- $\beta 1$ induces accumulation of dendritic cells in the odontoblast layer. J Dent Res 2003; 82:652-6.

9. Massague J. TGF- $\beta$ signal transduction. Annu Rev Biochem 1998; 67:753-91.

10. Duque C, Hebling J, Smith AJ, Giro EMA, Oliviera MF, Costa CADS. Reactionary dentinogenesis after applying restorative materials and bioactive dentin matrix molecules as liners in deep cavities prepared in nonhuman primate teeth. J Oral Rehabil 2006; 33:452-61.

11. Smith AJ, Tobias RS, Murray PE. Transdentinal stimulation of reactionary dentinogenesis in ferrets by dentin matrix components. J Dent 2001; 29:341-6.
12. Nakashima M, Toyono T, Murakami T, Akamine A. Transforming growth factor-beta superfamily members expressed in rat incisor pulp. Arch Oral Biol 1998; 43:745-75.

13. Tziafas D, Papadimitrious S. Role of exogenous TGF- $\beta$ in induction of reparative dentinogenesis in vivo. Eur J Oral Sci 1998; 106(Suppl.1):192-6.

14. Hu CC, Zhang C, Qian Q, Tatum NB. Reparative dentin formation in rat molars after direct pulp capping with growth factors. J Endod 1998; 24:744-51.

15. Finkelman RD, Mohan S, Jennings JC, Taylor AK, Jepsen S, Baylink D. Quantitation of growth factors IGF-1, SGF/IGF-11 and TGF- $\beta$ in human dentin. J Bone Miner Res 1990; 5:717-23.

16. Cassidy N, Fahey M, Prime SS, Smith AJ. Comparative analysis of transforming growth factor-beta (TGF- $\beta$ ) isoforms 1-3 in human and rabbit dentine matrices. Arch Oral Biol 1997; 42:219-23.

17. Zhao S, Sloan AJ, Murray PE, Lumley PJ, Smith AJ. Ultrastructural localization of TGF- $\beta$ exposure in dentine by chemical treatment. Histochem J 2000; 32:489-94.

18. Sloan AJ, Matthews JB, Smith AJ. TGF-beta receptor expression in human odontoblasts and pulpal cells. Histochem J 1999; 31:565-9.

19. McLachlan JL, Smith AJ, Sloan AJ, Cooper PR. Gene expression analysis in cells of the dentine-pulp complex in healthy and carious teeth. Arch Oral Biol 2003; 48:273-83.

20. Sloan AJ, Perry JB, Matthews JB, Smith AJ. Transforming growth factor-beta isoform expression in mature human healthy and carious molar teeth. Histochem J 2000; 32:247-52.

21. Piatelli A, Rubini C, Fioroni M, Tripodi D, Strocchi R. Transforming growth factor-beta 1 (TGF-beta 1) expression in normal healthy pulps and in those with irreversible pulpitis. Int Endod J 2004; 37:114-9.

22. Moses KD, Butler WT, Qin C. Immunohistochemical study of small integrin-binding ligand, $\mathrm{N}$-linked glycoproteins in reactionary dentin of rat molars at different ages. Eur J Oral Sci 2006; 114:216-22.

23. Olgart L, Bergenholtz G. The dentin-pulp complex: responses to adverse influences. In: Bergenholtz G, Horsted-Bindslev P, Reit C, editors. Textbook of endodontology. Oxford: Blackwell Publishing Company; 2003. p. 23.

24. Mjor IA. Pulp-dentin biology in restorative denstistry. Chicago: Quintessence Publishing company; 2002. p. 98-9.

25. Arana-Chavez VE. Massa LF. Odontoblasts: the cells forming and maintaining dentine. Int J Biochem Cell Bio 2004; 36:1367-73.

26. Smith AJ. Pulpal responses to caries and dental repair. Caries Res 2002; 36:223-32.

27. Murray PE, Windsor LJ, Smyth TW, Hafez AA, Cox CF. Analysis of pulpal reactions to restorative procedures, materials, pulp capping, and future therapies. Crit Rev Oral Biol Med 2002; 13:509-20.

28. Fitzgerald M, Chiego Jr DJ, Heys DR. Autoradiographic analysis of odontoblast replacement following pulp exposure in primate teeth. Arch Oral Biol 1990; 35:707-15.

29. Veerayutthwilai O, Byers MR, Pham TTT, Darveau RP, Dale BA. Differential regulation of immune responses by odontoblasts. Oral Microbiol Immunol 2007; 22:5-13.

30. Silva TA, Rosa AL, Lara VS. Dentin matrix proteins and soluble factors: intrinsic regulatory signals for healing and resorption of dental and periodontal tissues? Oral Diseases 2004; 10:63-74.

31. Smith AJ, Murray PE, Sloan AJ, Matthews JB, Zhao, S. Transdentinal stimulation of tertiary dentinogenesis. Adv Dent Res 2001; 15:51-4.

32. Lara VS, Figueiredo F, Silva TA, Cunha FQ. Dentin induced in vivo inflammatory response and in vitro activation of murine macrophages. J Dent Res 2003; 82:460-5.

33. Smith AJ, Matthews JB, Hall RC. Transforming growth factor $\beta 1$ (TGF $\beta 1$ ) in dentine matrix: ligand activation and receptor expression. Eur J Oral Sci 1998; 106:179-84.

34. Lucchini M, Romeas A, Couble ML, Bleicher F, Magloire H, Farges JC. TGF- $\beta 1$ signaling and stimulation of osteoadherin in human odontoblasts in vitro. Connect Tissue Res 2002; 43:345-53.

35. He W, Niu Z, Zhao S, Jin W, Gao J, Smith AJ. TGF- $\beta$ activated Smad signaling leads to a Smad3-mediated down-regulation of DSPP in an odontoblast cell line. Arch Oral Biol 2004; 49:911-8. 
36. Wrana JL, Attisano L, Wieser R, Ventura F, Massague J. Mechanism of activation of the TGF beta receptor. Nature 1994; 370:341-7.

37. Robert AB, Russo A, Felici A, Flanders KC. Smad3: a key player in pathogenetic mechanisms dependent on TGF- $\beta$. Ann N Y Acad Sci 2003; 995:1-10.

38. Begue-Kirn C, Smith AJ, Ruch JV, Wozney JM, Purchio A, Hartman $\mathrm{D}$, et al. Effects of dentin proteins, transforming growth factor beta 1 (TGF beta 1) and bone morphogenetic protein 2 (BMP2) on the differentiation of odontoblast in vitro. Int J Dev Biol 1992; 36:491503.

39. Leonard CM, Fuld HM, Frenz DA, Downie SA, Massague J, Newman SA. Role of transforming growth factor beta in chondrogenic pattern formation in the embryogenic limb: stimulation of mesenchymal condensation and fibronection gene expression by exogeneous TGFbeta and evidence for endogenous TGF-beta-like activity. Dev Biol 2000; 145:99-109.

40. DenBesten PK, Machule D, Gallagher R, Marshall Jr GW, Mathews C, Filvaroff E. The effect of TGF- $\beta 2$ on dentin apposition and hardness in transgenic mice. Adv Dent Res 2001; 15:39-41.

41. Sloan AJ. Smith AJ. Stimulation of the dentine-pulp complex of rat incisor teeth by transforming growth factor- $\beta$ isoforms $1-3$ in vitro. Arch Oral Biol 1999; 44:149-56.

42. Pasavant P, Yongchaitrakul T, Pattamapun K, Arksornnukit M. The synergistic effect of TGF-beta and 1,25-dihydroxyvitamin D3 on SPARC synthesis and alkaline phosphatase activity in human pulp fibroblasts. Arch Oral Biol 2003; 48:717-22.
43. Pasavant $P$, Yongchaitrakul T. Secreted protein acidic, rich in cysteine induces pulp cells migration via $\alpha v \beta 3$ integrin and extracellular signal-regulated kinase. Oral Diseases [published article online] 2007 Jul 27. Available from: URL:http://www.blackwellmunksgaard. com. Accessed December 26, 2007.

44. Téclès O, Laurent P, Zygouritsas S, Burger AS, Camps J, Dejou J, About I. Activtion of human dental pulp progenitor/stem cells in response to odontoblast injury. Arch Oral Biol 2005; 50:103-8.

45. Liu J, Jin T, Ritchie HH, Smith AJ, Clarkson BH. In vitro differentiation and mineralization of human dental pulp cells induced by dentin extract. In Vitro Cellular Dev Biol 2005; 41:232-8.

46. Tziafas D. The future role of a molecular approach to pulp-dentinal regeneration. Caries Res 2004;38:314-20.

47. Tziafas D. Induction of reparative dentinogenesis in vivo: a synthesis of experimental observation. Connect Tissue Res 1995; 32:297301.

48. Deng M, Shi J, Smith AJ, Jin Y. Effects of transforming growth factor $\beta 1$ (TGF $\beta-1)$ and dentin non-collagenous proteins (DNCP) on human embryonic ectomesenchymal cells in a three-dimensional culture system. Arch Oral Biol 2005; 50:937-45.

49. Melin M, Joffre-Romeas A, Farges JC, Couble ML, Magloire H, Bleicher F. Effects of TGF-beta 1 on dental pulp cells in cultured human tooth slices. J Dent Res 2000; 79:1689-96.

50. Huojia M, Muraoka N, Yoshizaki K, Fukumoto S, Nakashima M, Akamine A, et al. TNF- $\beta$ induces ectopic mineralization in fetal mouse dental pulp during tooth germ development. Develop Growth Differ 2005; 47:141-52. 